\title{
DE QUEM É O CORPO QUE COMPÕE A FORÇA DE TRABALHO? REFLEXÕES SOBRE TRABALHADORAS/ES TRANS NO CONTEXTO DA COVID-191
}

\author{
Jéssyka Kaline Augusto Ribeiro² \\ Guilherme Silva de Almeida ${ }^{3}$
}

\begin{abstract}
Resumo
O artigo é parte de um esforço para compor uma análise de reflexões sobre as condições de vida das trabalhadoras e trabalhadores trans no atual contexto da pandemia da Covid-19. Nesse processo é importante destacar a dificuldade da inserção das travestis, das mulheres transexuais e dos homens trans no mercado de trabalho que, em contexto de crise do capital, exploração intensa do trabalho e aumento do desemprego a situação se agrava ainda mais. Com a pandemia da Covid-19 ocorreram mudanças significativas, principalmente na vida das que são mais impactadas pela pobreza e desigualdade social.
\end{abstract}

Palavras-Chave: Trabalho; Transexualidade; Covid-19.

\section{¿DE QUIÉN ES EL CUERPO QUE COMPONE LA FUERZA DE TRABAJO? REFLEXIONES SOBRE TRABAJADORAS/ES TRANS NO CONTEXTO DA COVID-19}

\section{Resumen \\ El artículo es parte de un esfuerzo por componer un análisis de reflexiones sobre las condiciones de vida de los trabajadores y trabajadores trans en el contexto actual de la pandemia Covid-19. En este proceso, es importante resaltar la dificultad de insertar travestis, mujeres transexuales y hombres trans en el mercado laboral, quienes, en el contexto de una crisis de capital, intensa explotación laboral y creciente desempleo, la situación se agrava aún más. Con la pandemia de Covid-19, se produjeron cambios significativos, principalmente en las vidas de los más afectados por la pobreza y la desigualdad social. \\ Palabras Clave: Trabajo; Transexualidad; COVID-19. \\ OF WHOM IS THE BODY THAT COMPOSES THE LABOR FORCE? REFLEXIONS ABOUT TRANS WORKERS IN THE CONTEXT OF COVID-19}

\begin{abstract}
The article is part of an effort to compose an analysis of reflections on the living conditions of workers and trans workers in the current context of the Covid-19 pandemic. In this process, it is important to highlight the difficulty of inserting transvestites, transgender women and trans men in the labor market, who, in the context of a capital crisis, intense labor exploitation and rising unemployment, the situation is even worse. With the Covid-19 pandemic, significant changes occurred, mainly in the lives of those most impacted by poverty and social inequality.
\end{abstract}

Keywords: Work; Transsexuality; Covid-19.

\footnotetext{
1 Artigo recebido em 13/11/2020. Primeira avaliação em 25/11/2020. Segunda avaliação em 02/12/2020 Aprovado em 27/01/2021. Publicado em 25/02/2021

DOI: https://doi.org/10-22409/ tb.v19i38.47135

2 Jessyka Kaline Augusto Ribeiro. Doutoranda no Programa de Pós Graduação em Serviço Social da Universidade Estadual do Rio de Janeiro (PPGSS-UERJ). Assistente Social na ONG Casinha Acolhida no Rio de Janeiro-RJ. E-mail: jsk.ribeiroz@gmail.com ORCID: https://orcid.org/0000-0001-8006-5629. Lattes: http://lattes.cnpq.br/4094295442168877.

${ }_{3}^{3}$ Guilherme Silva de Almeida. Doutor em Saúde Coletiva pelo Instituto de Medicina Social da UERJ. Professor Adjunto da Escola de Serviço Social da UFRJ. E-mail: gsdealmeida@gmail.com

ORCID:https://orcid.org/0000-0001-7355-6606. Lattes: http://lattes.cnpq.br/2981461762793065.
} 


\section{Introdução}

O processo histórico de inserção das mulheres como trabalhadoras evidencia que essa inserção não foi a mesma para mulheres brancas e mulheres negras. Scott (1991) enfatiza que durante o período de industrialização na Inglaterra do século XIX, a força feminina era predominantemente jovem, solteira e associada ao trabalho barato, porém, nem todo trabalho barato era apropriado para ela. Os trabalhos para os quais as mulheres eram contratadas eram definidos como "trabalho de mulher", supostamente adequados, de algum modo, às suas capacidades físicas e ao seu nível de produtividade.

No que diz respeito às mulheres negras, Carneiro (2003) realça que o movimento de mulheres negras foi pondo em relevo a distância no mercado de trabalho entre mulheres brancas e negras, denunciando o peso do racismo e da discriminação racial nos processos de seleção e alocação da mão-de-obra feminina.

Atualmente, deparamo-nos com outro processo de complexidade analítica semelhante: o da inserção das travestis ${ }^{4}$, das mulheres transexuais e dos homens trans ${ }^{5}$ no mercado de trabalho. Uma pesquisa desenvolvida por Carrara \& Ramos (2006) demonstrou que a população trans constitui o grupo majoritário entre os(a)s que não são selecionado(a)s para um emprego ou entre os (as) que foram demitidos(a)s em razão de sua identidade de gênero. Somado a esse processo estão os baixos níveis de escolaridade dessa população e, consequentemente, as diminuídas possibilidades de acesso ao mercado de trabalho. O tratamento que é, por muitas vezes, dado a estas pessoas, é baseado em estereótipos e preconceitos que, consequentemente, desestimulam a adesão de muitas delas à escolarização e a outros espaços de sociabilidade.

No contexto de crise do capital, exploração intensa do trabalho, desemprego estrutural e destruição de direitos conquistados historicamente pelos(as) trabalhadores(as), o conservadorismo tem encontrado espaço para se reatualizar, motivando atitudes autoritárias, discriminatórias, irracionalistas e preconceituosas.

\footnotetext{
${ }^{4}$ Kulick (2008) aponta que a existência de travestis é registrada em toda a América Latina, mas em nenhum país elas são numerosas e conhecidas como no Brasil, onde alcançam visibilidade notável tanto no espaço social, quanto no imaginário cultural.

${ }^{5}$ Para efeito deste artigo, trataremos essas diferentes identidades a partir da expressão "população trans".
} 
Preconceitos $^{6}$ são orientações de valores cristalizados na sociedade, organizados a partir de precedentes históricos. Eles se constituem como uma expressão das relações conservadoras da sociabilidade burguesa e de seu individualismo que, por sua vez, remete à exploração, cada vez mais bárbara, do trabalho pelo capital. A banalização destes fundamentos representa um desvalor que emerge nas mais diferentes formas da vida cotidiana, inclusive no âmbito da diversidade sexual e de gênero (CFESS, 2016):

As opressões situam-se, sobre todas as formas que ousam constituirse como o "outro" em relação à régua cortante que mede a normalidade, na constituição de sujeitos que se materializam como seres humanos com cores de pele (nomeada colonialmente por "raça"); características sexuais, orientações distintas de seus afetos; performatividades singulares como pessoas e pertencimentos de classe social - estabelecidas por condições materiais concretas, mas também por identidades socioculturais construídas espacialmente (OLIVEIRA et al, 2019, p.34).

A concepção hegemônica do que venha a ser o trabalho desempenhado pela população trans é pautada em preconceitos e estereótipos diversos, e, mesmo que ocorra a oferta de trabalhos para essa população, esta acaba sendo feita de trabalhos extremamente precários. Há, de fato, inserção da população trans no mercado de trabalho, mas o que podemos afirmar é que o mercado de trabalho em suas características é majoritariamente cisgênero.

Com a pandemia da Covid-19 ocorreram mudanças significativas no que concerne à vida das pessoas trans no Brasil, em especial para aquelas mais impactadas diretamente pela pobreza e pela desigualdade social. Observamos um número cada vez mais crescente de trabalhadoras/es desempregadas/os.

A permanente existência de uma massa de trabalhadoras/es desempregadas/os é uma especificidade do modo de produção capitalista. A acumulação de capital depende da exploração da força de trabalho e da existência de um exército industrial de reserva, que permite aos capitalistas impor salários cada vez mais baixos, em especial para aquelas/es trabalhadoras/es que não dispõem de mão de obra qualificada. As pessoas trans são parte dessa massa.

\footnotetext{
${ }^{6}$ De acordo com Heller (2008), os preconceitos são obra da própria integração social, o desprezo e antipatia pelo "outro" ou pelo que é considerado diferente, são tão antigos quanto a própria humanidade.
} 


\section{O pauperismo da população trans}

O modo de produção capitalista se reproduz na busca constante do lucro, portanto, não existe capitalismo sem acumulação de capital. Para Marx (2017), durante a jornada de trabalho o tempo de trabalho se divide em duas partes, primeiro $\mathrm{a}(\mathrm{o})$ trabalhador(a) produz o valor correspondente ao seu salário (tempo de trabalho necessário), e em outro momento produz o valor excedente que é extraído pelo capitalista (tempo de trabalho excedente), a chamada mais-valia.

Portanto, o que interessa ao capitalista é justamente o processo de valorização, pois é justamente nele que se produz a mais-valia. A aplicação de mais-valia como capital ou conversão de mais-valia em capital é o que chamamos de acumulação de capital.

No processo da acumulação capitalista se produz uma população trabalhadora relativamente supérflua, em uma condição essencial para a subordinação do trabalho aos propósitos do capital. Para Marx (2017), ao produzir a acumulação do capital, a população trabalhadora produz, em proporções crescentes, os meios que fazem dela uma população supérflua. Essa população está sempre presente, mantém o funcionamento da lei geral da acumulação e constitui o exército industrial de reserva. Podemos afirmar que a população excedente é um produto necessário da acumulação ou do desenvolvimento da riqueza no sistema capitalista; ela se torna a alavanca da acumulação capitalista e, mesmo, condição de existência do modo de produção capitalista: "ela fornece a suas necessidades variáveis de valorização o material humano sempre pronto para ser explorado, independente dos limites do verdadeiro aumento populacional" (MARX, 2017, p. 707).

A superpopulação relativa existe em todos os matizes possíveis. Todo
trabalhador a integra durante o tempo em que está parcial ou
inteiramente desocupado. Se levarmos em conta as grandes formas,
periodicamente recorrentes, que a mudança de fases do ciclo
industrial lhe imprime, fazendo com que ela apareça ora de maneira
aguda nas crises, ora de maneira crônica nos períodos de negócios
fracos, a superpopulação relativa possui continuamente três formas:
flutuante, latente e estagnada (MARX, 2017, p. 716).

Dessa forma, observamos que grande parte da população trans está no segmento mais baixo da superpopulação relativa, a estagnada, a que habita a esfera do pauperismo. Tendo em vista que possui ocupações irregulares e precárias, de acordo com a Associação Nacional de Travestis e Transexuais (ANTRA, 2020), 
apenas $10 \%$ da população trans está inserida no mercado de trabalho formal. O que implica em que suas condições de vida e de trabalho estejam abaixo do nível médio da classe trabalhadora e, justamente por isso, possam ser facilmente um alvo da exploração do capital.

O pauperismo constitui o asilo para inválidos do exército trabalhador ativo e o peso morto do exército industrial de reserva. Sua produção está incluída na produção da superpopulação relativa, sua necessidade na necessidade dela, e juntos eles formam uma condição de existência da produção capitalista e do desenvolvimento da riqueza (MARX, 2017, p. 719).

O pauperismo como resultado do desenvolvimento das forças produtivas do trabalho social é uma especificidade da produção fundada no capital. Nesse processo, observa-se que a acumulação de miséria é relativa à acumulação do capital. Para lamamoto (2015), o capital, em seu movimento de valorização, produz a invisibilidade do trabalho e a banalização da vida humana.

O trabalho se encontra no centro da questão social ${ }^{7}$, que evidencia a imensa fratura entre o desenvolvimento das forças produtivas do trabalho social e as relações sociais que o impulsionam. Fratura que se manifesta na "banalização da vida humana, na violência escondida no fetiche do dinheiro e da mistificação do capital ao impregnar todos os espaços e esferas da vida social" (IAMAMOTO, 2015, p. 144). O trabalho assalariado é um dos pilares fundamentais para o sucesso da reprodução do capital, uma vez que é através dele que o capital consegue exercer controle absoluto sobre a força de trabalho.

Quando pensamos na inserção da população trans no mercado de trabalho, é preciso considerar que a vida deste segmento é marcada por processos de opressão e violência, o que nos coloca a necessidade de estarmos atentos (as) às narrativas de trajetória de vida, que para cada sujeito é única e específica. Então, seria impossível a tentativa de realizar uma única análise que estabelecesse de forma conclusiva a situação geral das pessoas trans trabalhadoras no Brasil. No entanto, é importante apontar características que tocam um número considerável de travestis e transexuais em suas histórias de vida, conforme já foi apontado em algumas

\footnotetext{
7 Entendemos a questão social como um fenômeno que se apresenta com novas configurações. Para Cisne (2015), essas novas configurações são determinadas pelo processo de reestruturação do capital, ou seja, pelas novas formas de gestão e/ou estratégias do modo de produção capitalista para se manter e se fortalecer na sociedade.
} 
pesquisas (PELÚCIO, 2009; KULICK, 2008; BENTO, 2006; LEITE JR., 2011; OLIVEIRA, 2016; MARINHO, 2018; entre outras).

Nessas pesquisas é possível elencar alguns condicionantes que atuam de maneira singular em cada trajetória individual e que se constituem como dificuldades para a inserção no mercado de trabalho. Alguns desses obstáculos seriam: a dificuldade de fazer-se respeitar em seu processo de transição de gênero; a expulsão de casa e a falta de apoio da família; a perda progressiva das relações comunitárias e familiares; a falta de acesso à saúde pública; e a falta de recursos para recorrer à assistência à saúde privada. Podemos elencar também o êxodo que várias pessoas trans empreendem de seus lugares de origem em direção aos grandes centros urbanos, conforme Pelúcio (2009) constata na trajetória das travestis: "mover-se na busca de um corpo, de um lugar habitável, de uma vida longe da abjeção, da pobreza e violência doméstica é um enredo comum" (PELÚCIO, 2009, p. 47).

Há também as diferentes formas de violência comunitária e de violência institucional no âmbito das ações governamentais, como a evasão (ou expulsão?) escolar e o assédio sofrido com o despreparo e/ou o desinteresse do Estado e das instituições de ensino para constituir acessibilidade para essa população.

De acordo com a Associação Brasileira de Lésbicas, Gays, Bissexuais, Travestis e Transexuais (ABGLT, 2016), o grupo populacional que mais sofre discriminação na escola é o de transexuais e travestis. Para muitos(as), a escola se constitui como uma das primeiras instituições que as/os violentam, fazendo com que abandonem o espaço que impõe normas de se viver a sexualidade e identidade de gênero baseadas na heteronormatividade ${ }^{8}$, o que acaba alimentando a ideia da travestilidade e da transexualidade como anormais e doentias:

Aqueles e aquelas que transgridam as fronteiras de gênero ou sexualidade, que as atravessam ou que, de algum modo, embaralham e confundem os sinais considerados "próprios" de cada um desses territórios, são marcados como sujeitos diferentes ou desviantes. Tal como atravessadores ilegais de territórios, como migrantes clandestinos que escapam do lugar onde deveriam permanecer, esses sujeitos são tratados como infratores e devem sofrer penalidades. Acabam por ser punidos, de alguma forma, ou na melhor das

\footnotetext{
8 O processo de normatização das identidades é chamado de heteronormatividade, que é o "enquadramento de todas as relações - mesmo as supostamente inaceitáveis entre pessoas do mesmo sexo - em um binarismo de gênero que organiza suas práticas, atos e desejos a partir do modelo do casal heterossexual reprodutivo" (PINO, 2007, p. 160). Pela lógica da heteronormatividade, todas as pessoas devem ser heterossexuais e todos os bens produzidos pela sociedade, sejam eles materiais ou simbólicos, são destinados para quem vive segundo seus preceitos.
} 
hipóteses, tornam-se alvo de correção. Possivelmente, experimentarão o desprezo ou a subordinação (LOURO, 2004, p. 89).

Nesse sentido, a própria concepção de trabalho para a população trans é pautada dentro de uma heteronormatividade - mas não só - o que acaba limitando e dificultando a demanda de empregos existentes, e favorecendo que trabalhos precários sejam naturalizados como mais frequente realidade. As dificuldades na obtenção de um emprego se constituem a partir de condicionantes que atuam de maneira específica na trajetória singular de cada sujeito. Observa-se que existe um controle dos corpos nas relações sociais, dessa forma, nem todos os corpos serão considerados aptos para todo tipo de atividade. Esse controle se exerce pois:

[...] cada sociedade ou cada grupo social imprime marcas em seus membros, tanto através de inscrições físicas (tatuagens, circuncisões, modelamento de determinada parte do corpo etc.), como estéticas (roupas, acessórios) e comportamentais (formas de andar, sentar, repousar etc.). O pertencimento social é, dessa forma, corporalmente inscrito, podendo ser identificado pelos demais membros daquela sociedade. Essas marcas corporais podem corresponder a diferentes situações - como classe social, faixa etária, etnia, posição social etc. - e, nesse sentido, indicam estados passageiros ou permanentes dos indivíduos (VÍCTORA et al, 2000, p.20)

A questão da sexualidade e da identidade de gênero, portanto, não é o único marcador de diferenças e organizador de desigualdades sociais, existindo também uma generificação das profissões/ocupações e uma cromatização das profissões/ocupações, entre outras formas de classificação dos corpos e lugares sociais. Não há uma única regra geral aplicável sempre; esses marcadores interagem de formas muito diversas. Conforme acentua Brah (2006), tais marcadores nunca agem isoladamente, costumam se combinar para reforçar diferenciações e exclusões; agem em articulação, mantêm relações de conexão e eficácia através dos quais as coisas são articuladas, tanto por suas diferenças como por suas semelhanças.

É importante destacar que não existem dados estatísticos sobre o número e o quantitativo exato da população trans empregada no mercado de trabalho. Não há um registro oficial, mas de acordo com a ANTRA (2020), cerca de 90\% das pessoas trans possuem o trabalho sexual como fonte de renda. Ativistas do movimento LGBTI+ afirmam que, como muitas pessoas trans estão registradas a partir do nome que 
consta nos documentos de Registro Geral $(R G)^{9}$ a partir das Secretarias de Segurança Pública (e não de seus nomes sociais), torna-se difícil distingui-las do restante da população desempregada, subempregada ou empregada. Além disso, existe uma parte dessa população que já fez a requalificação civil (alteração de nome e sexo nos documentos) e que, portanto, encontra-se igualmente dispersa na população cisgênera. Haveria, desse modo, dificuldades em identificar e dimensionar estes(as) trabalhadores(as) e poucas pesquisas que trabalham o tema entre pessoas trans tem sido visibilizadas publicamente.

E se existem dúvidas quanto à qualidade das ocupações executadas por essa população específica, para além do desemprego ou subemprego, há também o desafio da violência presente nas mais diversas expressões de acirramento da Questão Social. Connel (2014) aponta que as práticas de violência constituídas por uma ação que "ou destrói ou danifica corpos" são estruturadas socialmente e, em grande medida, são geradas pela própria dinâmica social, como a violência urbana e o genocídio da população negra. Ela é aplicada nas práticas rotineiras, antes socialmente invisíveis, de violência doméstica e de abuso sexual, até mesmo dentro do próprio ambiente familiar.

Os preconceitos e estereótipos que circundam a população trans favorecem seu encaminhamento a trabalhos extremamente precarizados. Ela está inserida no mercado de trabalho em espaços diversos. Está no trabalho doméstico ${ }^{10}$, no trabalho sexual ${ }^{11}$, no trabalho eventual (por demanda), às vezes nas artes e na moda, em atividades ilícitas, como operadores/as de telemarketing ${ }^{12}$ e muitas/os nas atividades informais (ambulantes, faxineiras, lavadores de carro, feirantes, cabeleireiras, barmen, freelancers). E aqui destacamos as/os trabalhadoras/es dos serviços de entrega por

\footnotetext{
9 Desde 2019, a alteração de documentos civis de pessoas trans foi repassada do Poder Judiciário, os cartórios (sem necessidade de cirurgia e/ou de diagnósticos médicos e psiquiátricos).

10 Importante destacar a respeito do trabalho doméstico que quando se observa dados recentes, verifica-se que o trabalho doméstico continua sendo exercido majoritariamente por mulheres, conforme pesquisa do Instituto Brasileiro de Geografia e Estatística (IBGE), no ano de 2015, o percentual de mulheres foi de $92,00 \%$, já o de homens foi de apenas $8,00 \%$. Tais informações demonstram claramente um número consideravelmente superior de mulheres inseridas nessa atividade.

${ }^{11}$ Adoto aqui o uso termo trabalho sexual em oposição à prostituição (frequentemente vinculado ao crime, ao desvio, à necessidade de "correção", ao estigma e à vergonha), como trabalhador/a do sexo entende-se aqui, todas/os aquelas/es que trocam serviços sexuais por alguma forma de ganho econômico, incluídas aí todas as atividades da indústria do sexo (RAMALHO, 2012).

12 Marinho (2018) abordou a presença de pessoas trans como operadores/as de telemarketing. A pesquisadora demonstrou ser uma atividade comum a jovens e marcada por intensa exploração e precarização das condições de trabalho, mas ainda assim, um importante nicho de sobrevivência.
} 
aplicativo ${ }^{13}$, que vem aumentando consideravelmente nos últimos anos e, ainda mais, no contexto da pandemia da covid-19.

Além destas atividades previamente mencionadas, vale lembrar que há aquelas/es que realizam outras atividades formais ${ }^{14}$, o que nos leva a afirmar que há, de fato, inserção da população trans no mercado de trabalho.

Pouco se tem produzido academicamente no Brasil sobre o mercado de trabalho para a população trans. Algumas pesquisas vêm demonstrando que existem desigualdades sociais que permeiam a vida, especialmente das travestis. Destaco aqui o trabalho desenvolvido por Oliveira (2016), que demonstra que as travestis pertencem a um dos segmentos mais subalternizados da classe trabalhadora e que vive particularidades no cotidiano do mercado de trabalho.

Já a pesquisa de Hartmann (2017), apontou para a existência de fortes resistências por parte das empresas privadas e do Estado em criar alternativas para inserir formalmente pessoas trans no mundo do trabalho. A pesquisa identificou que elas estão, de um modo geral, em empregos subalternos e quase sempre sem segurança financeira, sem estabilidade de vínculo empregatício e sem qualquer direito trabalhista.

Há diversas formas de violação de direitos, que ocorrem em casa, na rua, na escola e no ambiente de trabalho. Não é raro identificar depoimentos em que travestis e transexuais são violentados/as ao serem tratados/as de modo desrespeitoso e humilhante. A pesquisa desenvolvida por Rondas \& Machado (2015), por exemplo, sobre a inserção de travestis no mundo do trabalho, demonstra que as formas de violência vividas nos espaços de trabalho são de abuso de autoridade, assédio sexual baixa remuneração e impossibilidade de promoções ou de ocupação de cargos de chefia.

\footnotetext{
${ }^{13}$ De acordo com uma reportagem da BBC News Brasil realizada em maio de 2019, que conversou com dezenas de entregadores da cidade de São Paulo, os ciclistas ouvidos pela reportagem relataram fazer jornadas de mais de 12 horas diárias, trabalharem muitas vezes sem folgas e até dormirem na rua para emendarem um horário de pico no outro, sem precisar voltar para a casa distante. Para Antunes (2018), estamos presenciando a expansão da chamada uberização do trabalho, um novo estágio de exploração do trabalho e da terceirização. Trabalhadores/as com seus instrumentos de trabalho, arcam com suas despesas de seguridade, com os gastos de manutenção do carro, moto ou bicicleta, alimentação e limpeza: "enquanto o aplicativo - na verdade, uma empresa privada global apropria-se do mais-valor gerado pelo serviço dos motoristas, sem preocupações com deveres trabalhistas historicamente conquistados pela classe trabalhadora (p.35).

${ }^{14}$ Aqui, foi considerada uma ocupação formal, aquelas pessoas que são assalariadas com carteira, servidores/as públicos e trabalhadores/as por conta própria, contribuintes para a previdência social (CARDOSO, 2013).
} 
Também é observada a própria não legitimação do nome social, regulamentado pela Portaria n. 1.036/2015 do Ministério do Trabalho (MT), e pelo Decreto Presidencial № $8.727 / 2016$, que dispõe sobre a possibilidade do uso do nome social e do reconhecimento da identidade de gênero de pessoas travestis e transexuais no âmbito da administração pública federal.

\section{Transformações no mundo do trabalho e os rebatimentos na população trans}

A partir da década de 1970, as transformações operacionalizadas pela ofensiva do capital, em resposta à crise estrutural, resultaram na banalização da vida humana e no agravamento das desigualdades socioculturais, em meio ao desenvolvimento desigual e combinado entre as nações e, no interior destas, entre as classes e grupos sociais.

Nesse sentido, é preciso destacar a complexidade que marca a constituição da classe-que-vive-do-trabalho ${ }^{15}$, diante desse emaranhado de contradições, postas pela sociabilidade capitalista. Foi nesse período que o capital implementou um processo de reestruturação em escala global, objetivando tanto a recuperação do seu padrão de acumulação, quanto fortalecer sua hegemonia no espaço produtivo.

Assiste-se a intensas mudanças na organização, gestão e consumo da força de trabalho, avançando na opressão da classe que vive do trabalho, em nome dos mecanismos materializados pela reestruturação produtiva, o que acarretou a perda de direitos historicamente conquistados. Dessa forma, o capital, veio "redesenhando novas e velhas modalidades de trabalho - o trabalho precário - com o objetivo de recuperar as formas econômicas, políticas e ideológicas da dominação burguesa (ANTUNES, 2009, p. 233)". Nestes termos, o capital elaborou suas estratégias de reação para reverter a queda da taxa de lucros, através da mundialização da economia e da ascensão do neoliberalismo.

Para Barroco (2011), esses processos imprimem uma nova dinâmica no conjunto das relações sociais, marcadas pela radicalização da alienação e mercantilização da vida social, fazendo emergir o problema axial da vida cotidianana

\footnotetext{
${ }^{15}$ A utilização do termo classe-que-vive-do-trabalho vem, de acordo com Antunes (2003), com o objetivo de dar ênfase à noção ampliada de classe. O autor constrói uma argumentação que demonstra e reafirma a nova composição assumida pela classe trabalhadora hoje, sem negar as profundas transformações que o proletariado passou em seu interior, fundamentalmente nas quatro últimas décadas. Ao contrário, Antunes enfatiza algumas dessas mudanças, sem desconsiderar, no entanto, que a efetividade, processualidade e concretude da classe permanecem vivas.
} 
atualidade: a reificação das relações sociais. Nessas condições, foi implementado um modo de vida orientado pelo consumo, pela competitividade e pelo individualismo, e esse processo intervém em todas as dimensões da vida social, constituindo o chamado ethos burguês, cujos valores se apoiam no princípio da propriedade privada. Nesse cenário de profundas mudanças que incidiram na vida cotidiana dos sujeitos, a ideologia dominante cria e reforça uma cultura transfóbica constituída por discursos sociais de inferiorização da sexualidade não heterossexual:

A ideologia dominante, patriarcal-racista-capitalista, penetra na consciência dos indivíduos devido a naturalização das relações de dominação e exploração que a alienação produz. Essa naturalização dificulta a possibilidade de se pensar e agir de forma transformadora. Com isso, muitos indivíduos não percebem essas relações como tais [de dominação e exploração] ou, quando percebem, não acham possível alterá-las (CISNE, 2014, p. 95).

De acordo com Antunes (2011, p. 80) "o valor de uso das coisas é minimizado, reduzido e subsumido ao seu valor de troca. Mantém-se somente enquanto condição necessária para integralização do processo de valorização do capital, do sistema produtor de mercadorias", ou seja, o trabalho abstrato posto como dispêndio da força de trabalho, é elemento determinante da acumulação capitalista através da mais-valia. Nessa perspectiva, o trabalho no modo de produção capitalista, à medida que desencadeia o aumento do desenvolvimento das forças produtivas através do incentivo às novas tecnologias no âmbito do processo de produção de valores de uso e valores de troca, instaura necessariamente uma modificação na relação capital $x$ trabalho, sendo ressaltado o protagonismo do capital nessa dada ordem social.

Contudo, tal protagonismo não descarta o trabalho e a tensão estabelecida nesse processo de acumulação, tendo em vista que o capital não se reduz a um conjunto de coisas, na forma do fetiche/dinheiro, mercadorias e/ou objetos, na medida em que este só existe ao subordinar a força de trabalho à lógica que lhe dá sustentação se configurando como uma relação social.

Desse modo, na medida em que o modo de produção capitalista se desenvolve, ele revela contradições que se manifestam nas suas crises periódicas. O sistema do capital é passível de crises cíclicas inerentes ao seu desenvolvimento: a crise possui um sentido processual, de média ou longa duração e com períodos de retomada do crescimento e de expansão do capital. Portanto, trata-se de um fenômeno dinâmico (MOTA, 2011). 
É através da crise que foram desencadeadas transformações no ambiente social, político, econômico e cultural, como formas de garantir um processo de reorganização política e ideológica de dominação do capital sobre o trabalho. Nesse processo, o Estado, em uma orientação neoliberal, cumpre um papel primordial.

Neste aspecto, a classe dominante assume o papel de instituir estratégias de recuperação da taxa de lucro intensificando o ritmo do processo de trabalho, com vistas à extração de mais-valia, na medida em que modifica as formas de consumo e gestão da força de trabalho, modificando o modo de produção e concebendo novas bases políticas, sociais e ideológicas que objetivam construir uma nova hegemonia ao capital, caracterizando a sua nova fase de acumulação, com fortes rebatimentos na estrutura produtiva e nas formas de representação sindical e política.

Em contrapartida, é exigido ao trabalhador a qualificação profissional neste novo processo de produção, rompendo com a relação homem máquina que acontecia no fordismo através da execução de várias tarefas, aumentando o grau de exploração (número mínimo de trabalhadores) e sobrecarregando-os com uma série de funções, assumindo um papel de polivalência, sob condições de flexibilização dos direitos trabalhistas e subcontratação (ANTUNES, 2011).

Um dos aspectos de destaque no processo de reestruturação produtiva é a criação de um novo tipo de trabalhador que melhor se enquadre aos objetivos do capital. Esse processo imprime novas exigências ao trabalhador, acirra-se a competitividade, ocorre a flexibilização ${ }^{16}$ dos processos de trabalho, mercados de trabalho, dos produtos, dos padrões de consumo, e dos direitos sociais da classe trabalhadora.

O neoliberalismo na América Latina provocou a realização de contrarreformas que visam atender às demandas do capital, resultando em uma situação de persistente desemprego e relações informais e precarizadas de trabalho (BOSCHETTI, 2009). Observa-se com as mudanças no mundo do trabalho uma dinamicidade de processos que atinge os/as trabalhadores/as, dentre eles, a diminuição da classe operária nos moldes tradicionais, a intensificação do trabalho assalariado, a ampliação do setor de serviços, a incorporação da mão de obra

\footnotetext{
${ }^{16}$ A flexibilidade do trabalho repousa sobre níveis variáveis, mas sempre presentes, de rigidez nos comportamentos sociais. Entre esses fatores de rigidez, a divisão sexual do trabalho é central. Paradoxalmente, ela possibilita a organização flexível do trabalho: o trabalho assalariado das mulheres, principalmente sob a forma de trabalho em tempo parcial compulsório, e o trabalhado assalariado dos homens, possibilitado pelo trabalho doméstico das mulheres (CATTANEO \& HIRATA, 2009, p. 109).
} 
feminina e o encadeamento do trabalho parcial, temporário e precarizado. Esse último, com as determinações de gênero e raça/etnia, adensam os aspectos de exploração e dominação da classe trabalhadora, tendo como seu maior expoente a expansão do desemprego em escala globalizada.

Há de se destacar que o interesse do capital está tanto na forma de assegurar a apropriação do exército industrial de reserva - e assim garantir os salários cada vez mais baixos - como também há grande proveito em alguns setores da economia dessa população.

Conforme pesquisa desenvolvida por Marinho (2018), no setor do telemarketing existe uma cultura de absorção da população trans. Para o empregador, a força de trabalho dos corpos trans é mais docilizável e subordinável ao trabalho. Sendo assim, o conjunto de/a trabalhadores/as que tem maiores dificuldades de obter trabalho e/ou de se manterem nele, parece se dispor com mais facilidade a condições de trabalho adversas e à superexploração.

Há de se atentar também para o valor agregado ao capital das empresas quando elas apresentam uma imagem socialmente comprometida com segmentos discriminados, algo que vem crescendo gradativamente nos últimos anos no Brasil, principalmente após a criação da norma de certificação social chamada de SA8000 ${ }^{17}$ - que certifica que uma empresa possui ou não produtos ou serviços executados de forma socialmente correta.

O respeito à diversidade faz parte das estratégias das empresas na busca de maior produtividade, eficiência e visibilidade, portanto, embora essas iniciativas possam ser fundamentais para quem precisa trabalhar e encontra dificuldades, o objetivo delas também é o crescimento de seus lucros.

Presenciamos atualmente o advento e crescimento exponencial do novo proletariado da era digital, cujos trabalhos ganham impulso com as Tecnologias da Informação e Comunicação (TICs). O trabalho online, que cresce intensamente desde o processo da reestruturação produtiva nos anos 1970, "com o seu instrumental tecnológico-informacional-digital, fez deslanchar essa processualidade, que se tornou

\footnotetext{
17 Lançada em outubro de 1997 pela Council on Economics Priorities Accreditation Agency (CEPAA), atual Social Accountability International (SAI), organização não-governamental norte-americana. Foi criada baseando-se nas normas da Organização Internacional do Trabalho (OIT), na Declaração Universal dos Direitos Humanos e na Declaração Universal dos Direitos da Criança da ONU.
} 
incessante, convertendo a reestruturação produtiva em um processo permanente" (ANTUNES, 2018, p. 47-48).

Conforme análise de Antunes (2018), atualmente presenciamos uma nova morfologia da classe trabalhadora, com destaque para o papel crescente do novo proletariado de serviços da era digital. Instabilidade e insegurança são traços constitutivos dessa nova modalidade, como também o trabalho sem contrato, no qual não há previsibilidade de horas para cumprir, muito menos direitos assegurados: "Quando há demanda, basta uma chamada e as trabalhadoras e os trabalhadores devem estar online para atender o trabalho intermitente (...) As transversalidades entre classe, gênero, etnia, geração, tudo aparece nas complexas fábricas" (p. 21-23).

Conforme ocorreu historicamente às mulheres no mundo do trabalho, empiricamente é possível observar que a população trans tende a desempenhar funções com as piores remunerações, como também não há incentivos na qualificação de suas atribuições.

As relações sociais no capitalismo potencializam as desigualdades para as pessoas trans, sobretudo no aspecto da violência e exploração. Os dados da ONG “Transgender Europe" apontam que, entre 2008 e 2014, foram reportados 689 assassinatos de pessoas trans no Brasil. De acordo com o Relatório Anual de Assassinato de LGBT no Brasil' ${ }^{18}$, divulgado pelo Grupo Gay da Bahia (GGB) ocorreram 164 assassinatos de travestis e transexuais, no ano de 2018, o que confirma o dado de que o Brasil é o país que mais mata travestis e transexuais no mundo.

Conforme expõe Brito (2016), o preconceito, a discriminação e 0 constrangimento perpassam o cotidiano de trabalho das pessoas trans e evidenciam que a condição de trabalhador/a trans tem reflexos diretos nas condições de sobrevivência material e subjetiva desses sujeitos. Essa violência tem no "aparato repressivo do Estado, capturado pelas finanças e colocado a serviço da propriedade e poder dos que dominam, o seu escudo de proteção e disseminação" (IAMAMOTO, 2015, p. 144).

18 Segundo o Relatório Anual da página eletrônica "Quem a homofobia matou hoje" https://homofobiamata.wordpress.com/estatisticas/relatorios/. Acesso em 10 de agosto de 2020. 


\section{Reflexões sobre trabalhadores e trabalhadoras trans em contexto de pandemia da covid 19 no Rio de Janeiro}

Em tempos de crise capitalista, as consequências que afetam o emprego, o trabalho e a divisão do trabalho entre sexo, gênero, classe, raça, orientação sexual e identidade de gênero se agudizaram de forma preocupante na sociedade.

No cenário já descrito de neoliberalismo, o crescimento do nível de exploração e das desigualdades sociais, as expressões da questão social ${ }^{19}$, assume novas roupagens. Inscrita na natureza das relações sociais capitalistas, a questão social passa por um processo de progressiva criminalização e por uma tendência de naturalização, isentando a sociedade de classes da responsabilidade na produção das desigualdades sociais.

É interessante observar como esses sujeitos estão vivenciando a atual crise, quais são as condições objetivas e subjetivas para realizar o isolamento social, principal tática de enfrentamento da propagação do vírus da covid-19. Como já dito, uma questão comum a muitas pessoas trans tem sido historicamente a expulsão ou evasão das próprias famílias, por vezes, ainda crianças ou adolescentes.

A partir daí (ou simultaneamente) trajetórias escolares são rompidas e a sobrevivência material se impõe no limite. Raramente pessoas trans têm oportunidade de completar seu processo de escolarização sem vivenciarem conflitos tanto em casa quanto na escola. Além disso, também raramente podem escolher quando e como irão se inserir numa atividade de trabalho remunerado. Formação precária, ausência de uma rede de suporte familiar e transfobia comunitária cooperam em processos que empurram essas pessoas para moradias precárias e temporárias, sejam estas individuais ou coletivas, especialmente nas periferias e favelas das grandes cidades. Ora, se a tática de isolamento social pressupõe uma habitação estável, segura e infraestrutura sanitária adequada, pode-se concluir que a maior parte dessas habitações não tem essas características.

Ainda que parte dessas pessoas viva em moradias com água encanada e ventilação adequada, muitas vezes a manutenção dessa moradia só é possível a partir de uma busca diária e insegura por renda, feita, como dito através de um conjunto de ocupações precárias, a maior parte delas no setor de serviços, gravemente afetado

19 Expressa disparidades econômicas, políticas e culturais das classes sociais, "mediatizadas por relações de gênero, étnico-raciais e formações regionais colocando em causa as relações entre amplos segmentos da sociedade civil e o poder estatal" (IAMAMOTO, 2015, p. 17). 
pelo isolamento social. A maior parte da população trans esteve e está entre a população que não pôde realizar o isolamento social pela necessidade de assegurar minimamente suas condições de sobrevida, como moradia e alimentação.

O abrigamento de pessoas em situação de vulnerabilidade figura legalmente entre as competências da Política Nacional de Assistência Social (PNAS), que deveria promover o acolhimento dessa população através dos seus serviços. A maior parte dos municípios brasileiros, entretanto, não executa a PNAS adequadamente e de acordo com as reais necessidades das populações que dela necessitam. Assim, a população trans, muitas vezes, não é abrigada pelos poucos equipamentos públicos disponíveis e, quando isso ocorre, pode vivenciar novos episódios de transfobia institucional. Além disso, não é possível afirmar que a maior parte dos abrigos destinados à população que vive nas ruas logrou êxito em garantir condições sanitárias adequadas durante a pandemia, como também em garantir um espaço isento dos assédios e violências que a população trans em geral sofre.

A ausência de abrigamento e de alternativas de habitação para a população trans não é um problema novo, apenas se tornou mais grave num contexto de pandemia e de desemprego estrutural agravado pela conjuntura. Muitas travestis e mulheres trans viveram e continuam vivendo em habitações comunais conquistadas pela via do auxílio mútuo e/ou de uma estratégia de ocupação, principalmente do casario abandonado das grandes cidades.

Algumas dessas iniciativas, geralmente das próprias travestis ou transexuais, foram muito populares, como a Casa Brenda Lee, fundada em 1986, em São Paulo, no contexto da AIDS e ainda em funcionamento. Também a da travesti Luana Muniz, falecida em 2017. Ela era conhecida como "rainha da Lapa", pela criação do bordão "travesti não é bagunça" e, principalmente, por acolher travestis, transexuais, portadores de HIV, prostitutas e outras pessoas que viviam na rua no casarão da avenida Mem de Sá, no bairro da Lapa na cidade do Rio de Janeiro (RJ).

Mais recentemente, várias outras "casas"20" têm sido fundadas no Brasil com propósito semelhante, o de acolhimento da população LGBTI+ e maior organização social de suporte, tais como a Casa Aurora em Salvador, o Instituto Transviver em Recife, a Casa Chama, o Coletivo Arouchianos, a Casa Florescer e a Casa 1, todos em São Paulo, a Casa Nem e a Casinha Acolhida no Rio de Janeiro, a Casa Miga em

${ }^{20}$ É importante registrar que a maioria das "casas" oferece além de moradia, cursos e outros recursos para inserção no mercado de trabalho e acesso à escolarização e cultura. 
Manaus, a Astra LGBT e a CasAmor, ambas em Aracaju, a Transvest em Belo Horizonte e a Casa Transformar em Fortaleza.

$\mathrm{Na}$ ausência do Estado em assegurar o direito constitucional à habitação digna, reatualiza-se diante das necessidades trans, estratégias políticas levadas à frente pela militância trans. Ilustra essa tendência a situação ocorrida na cidade do Rio de Janeiro (RJ) em plena pandemia de covid-19.

Em 2019, um prédio da Rua Dias da Rocha em Copacabana, foi ocupado pela Frente Internacionalista dos Sem-Teto (FIST). Na ocupação ali instituída, passou a viver um grupo de cerca de 40 pessoas LGBTIQA+, lideradas pela famosa coordenadora da ocupação e ativista Indianare Siqueira. Segundo ela, a ocupação não tinha cunho partidário e era formada por pessoas que "se protegiam, trocavam oportunidades e humanidade", geralmente pessoas jovens que tinham rompido com suas famílias de origem em razão da orientação sexual e/ou identidade de gênero. $A$ ocupação do imóvel de Copacabana era parte de uma trajetória de ocupação de outros imóveis abandonados pelas ativistas trans da FIST, sempre expulsas por processos de reintegração de posse.

Entre julho e agosto de 2020, mediante um processo judicial, ocorreram tentativas de reintegração de posse ao proprietário, que mantinha o imóvel inabitado há aproximadamente dez anos. Com o apoio de outros/as ativistas não residentes e de algumas autoridades públicas do campo dos direitos humanos, as ocupantes resistiram à desocupação. A partir daí, ocorreu uma longa negociação bem sucedida que permitiu que elas fossem realocadas numa casa provisória no bairro do Flamengo, a fim de aguardarem posteriormente sua alocação numa ocupação definitiva em Laranjeiras (Blog LuLacerda, 2019; Cachapuz, 2020; Vinodj, 2020).

Além de viverem cotidianamente experiências de desemprego ou subemprego, pessoas trans encontram dificuldades adicionais para acessarem os programas de transferência de renda destinados a quem deles necessita. Isso ocorre com regularidade em benefícios assistenciais de amplo alcance populacional como o Programa Bolsa Família (PBF) e o Benefício da Prestação Continuada (BPC). Os motivos para não acessarem são todos os outros que dificultam o acesso da população pobre em geral, agravados pela transfobia.

Ao discutir o PBF, Jaccoud (2020) analisa que a despeito das ofertas terem progredido quanto à universalização do acesso, há "dificuldades de se contrapor à reprodução das desigualdades sociais, efetivar igualdade de chances e fortalecer um 
projeto de integração e desenvolvimento social". Seriam dificuldades "particularmente graves, segundo a autora, quando referidas a alguns públicos específicos" (p.296).

No caso das pessoas trans, uma das principais dificuldades é saber da existência de tais benefícios e a forma de acessá-los, porque parte dessa população vive à margem das instituições de execução das políticas sociais. Além disso, uma parte procura evitar o contato com tais instituições por receio de transfobia institucional (o que ocorre com frequência), sobretudo, expressando-se no não reconhecimento do nome e identidade/expressão de gênero dessas pessoas.

No contexto da pandemia, a grande massa de trabalhadores/as informais do país esteve diante do parco e dificultoso acesso ao único programa social diretamente associado ao grave quadro sanitário, o auxílio emergencial. O governo federal não disponibilizou o benefício através da malha de instituições que já operam na execução da PNAS, tampouco favoreceu o acesso. Ao contrário: o fez através do aplicativo de um banco público com graves problemas operacionais e inacessível a quem não dispunha de telefones celulares e documentos oficiais.

É comum à população que reside, mesmo temporariamente, nas ruas, a perda de documentos, assim como à população que é expulsa ou foge de casa. A população em condição de pauperismo, aí incluída a população trans, muitas vezes não dispõe, seja de um celular, de uma conexão à internet, ou de conhecimentos de informática (ou outros) para realizar seu cadastramento. Além disso, o sistema operacional do aplicativo de acesso bloqueava incongruências, como alteração de nomes de familiares, entre outras. Quando finalmente um indivíduo conseguia ser incluído como beneficiário do auxílio emergencial ainda restava a ele muita paciência para aguardar pelo recebimento da quantia que em muitos casos levou meses.

Finalmente, sabe-se ainda que pessoas trans enfrentam historicamente no país um conjunto de dificuldades oriundas do reconhecimento tardio da possibilidade de requalificação civil e da resistência de um amplo leque de instituições ao reconhecimento do nome social e da identidade/expressão de gênero. Relatos informais nos permitem afirmar que algumas pessoas trans ficaram excluídas do auxílio emergencial da pandemia de covid-19 em razão de dificuldades para o reconhecimento de suas identidades.

É fato também que nem todas as pessoas trans têm forte engajamento político e/ou integram comunidades de resistência. Se a pandemia tem efeitos detratores 
sobre a saúde mental da população em geral, tais efeitos são potencializados por vivências de solidão, estigma, desproteção familiar e culpabilização, que são comuns.

A descrição de um isolamento social idílico vivenciado em condições familiares estereotipadas numa moradia de camadas médias higienizada, clara, ventilada, com farto alimento, tempo livre para o desenvolvimento de hobbies e novas habilidades empreendedoras, bem como marcadas por uma convivência supostamente harmoniosa entre seus membros, não pode ser entendido como algo além de uma ficção para a maioria das pessoas. Tão frustrante quanto não vivenciar a ficção tão exaustivamente explorada pelas diferentes mídias é vivenciá-la o tempo todo como apologia.

Como analisou Mioto (1997), a ideia de família como lugar de felicidade ocorre pelo não-desvelamento do seu caráter histórico. Ela é tomada como um grupo "natural" e há uma naturalização de suas relações: enaltecimento do amor materno, paterno e filial. Tal ficção também é amplamente difundida nas instituições públicas e seus profissionais, inclusive as de saúde, responsáveis pelo enfrentamento à pandemia. Muitas pessoas trans têm histórias muito distintas dessa para contarem e viveram a pandemia sofrendo toda sorte de violações no interior da própria família e, em alguns momentos, tendo que escolher entre a exposição à pandemia no espaço público e a angústia e violência nas relações familiares.

\section{Conclusão}

O corpo é construído historicamente, e os corpos que compõem a força de trabalho são marcados por raça, classe, sexo, gênero, nacionalidade, cor, etnia, entre outros marcadores. A vida da população trans é fortemente marcada por processos de opressão e violência desde os primeiros momentos formativos. Muitas são excluídas do espaço escolar, expulsas de casa ainda na infância e vivem em condições de miséria marcadas pela violência e opressão do Estado. Grande parte quando se inserem no mercado de trabalho entram de forma precarizada e em empregos que exploram sua força de trabalho.

É preciso atentar-se para as questões específicas das pessoas trans, como os aspectos da transfobia, violência, evasão escolar, desemprego, perda de laços familiares, e a pobreza que afeta grande parte. Infelizmente, os dados empíricos não refletem a realidade devido a falta de notificações do Estado, como também a 
ausência de dados governamentais. O Brasil é o país que mais mata pessoas trans e travestis, o que reforça a importância de políticas, ações, programas, instituições que possam trazer impactos no combate a violência transfóbica em nossa sociedade.

A pandemia deixa transparecer ainda mais essa desigualdade: a ONG Casinha Acolhida ${ }^{21}$, localizada no Rio de Janeiro, deu início a um projeto em abril de 2020 para distribuição de cestas básicas entre a população LGBTI+. Gradativamente, o público foi se expandindo, e em setembro já havia, em média, 80 pessoas beneficiadas com o programa, grande parte composta por pessoas trans e negras. Além do aumento da procura por alimentação, houve diversos relatos de sofrimento psíquico, desemprego, dificuldades de acesso ao auxílio emergencial, aumento da homofobia no confinamento com familiares, e dificuldades na materialização de uma terapia online, devido ao medo de que algum membro familiar o/a escutasse falar.

Sobre as iniciativas de inserção no mercado de trabalho, há poucas, quase inexistentes, grande parte criadas por órgãos não governamentais. Iniciativas pontuais e que não possuem continuidade, condições de trabalho precárias, pouca possibilidade de progressão na carreira, de acesso a benefícios, ausência de direitos trabalhistas e altos requisitos de formação profissional demandados pelas/os contratantes.

As iniciativas para inserção da população LGBT no mundo do trabalho ainda são bastante tímidas e não apontam para a efetividade de metas. No Brasil, há quase uma inexistência de políticas definidoras de qualificação para o mercado de trabalho deste público, e mesmo quando existem, tendem a se estabelecer sobre estratégias de patologização e de mercantilização da sua mão de obra barata.

Há claramente, em grande medida, ausência e/ou alcance limitado de uma legislação que garanta direitos e que possibilite o exercício pleno da cidadania de tal população. Além disso, não há disposição governamental no presente contexto para o estabelecimento de políticas nesta direção.

Por fim, precisamos nos dar conta de que há uma multiplicidade de corpos, que são compreendidos e vistos de formas distintas em diferentes culturas. $\mathrm{O}$ corpo que compõe a força de trabalho se modifica histórica e culturalmente.

${ }^{21}$ Esse relato veio da experiência de um das(os) autoras(es) como Assistente Social na ONG citada. 


\section{Referências}

ABGLT, Associação Brasileira de Lésbicas, Gays, Bissexuais, Travestis e Transexuais. Pesquisa Nacional sobre o Ambiente Educacional no Brasil 2015: as experiências de adolescentes e jovens lésbicas, gays, bissexuais, travestis e transexuais em nossos ambientes educacionais. Curitiba: ABGLT, 2016.

ANTRA. Associação Nacional de Travestis e Transexuais. Disponível em: https://www.facebook.com/antrabrasil/. Acesso em 10 dez. 2020.

ANTUNES, Ricardo. O privilégio da servidão: o novo proletariado de serviços na era digital. 1. Ed. São Paulo: Boitempo, 2018.

. "Os modos de ser da informalidade: rumo a uma nova era da precarização estrutural do trabalho?" Revista Serviço Social e Sociedade. São Paulo: Cortez, 2011.

"Século XXI: nova era da precarização estrutural do trabalho?" In: ANTUNES, Ricardo \& BRAGA, Ruy. Infoproletários: degradação real do trabalho virtual; Cortez, 2009.

"Adeus ao Trabalho? Ensaios sobre as metamorfoses ea centralidade no mundo do trabalho". São Paulo. Cortez, 2003.

AVELAR, Rezende Bruno de Avelar; BRITO, Walderes; MELLO, Luiz. "A (in) segurança pública que o Estado brasileiro oferece à população LGBT: Mapeamento crítico preliminar de políticas públicas". In: MELLO, Luiz (org.). Políticas públicas para população LGBT no Brasil: um mapeamento crítico preliminar. Goiás: Ed. da UFG, 2010.

BARROCO, Maria Lúcia S. "Barbárie e neoconservadorismo: os desafios do projeto ético-político". Revista Serviço Social e Sociedade. São Paulo, n. 106, abr./jun. 2011.

BELÉM, Rafael. "12 casas de acolhimento para LGBTIs no Brasil”. Disponível em: https://casavogue.globo.com/Arquitetura/Cidade/noticia/2020/06/12-casas-deacolhimento-para-Igbtis-no-brasil.html. Acesso em 07 de setembro de 2020.

BENTO, Berenice. A reinvenção do corpo: sexualidade e gênero na experiência transexual. Rio de Janeiro: Garamond/CLAM, 2006.

$\begin{array}{lccccc}\text { BLOG LULACERDA. “Moradores de Copacabana } & \text { estão revoltados com } \\ \text { ocupação de } & \text { prédio } & \text { abandonado". } & \text { Disponível } & \text { em: }\end{array}$ https://lulacerda.ig.com.br/moradores-de-copacabana-estao-revoltados-comocupacao-de-predio-abandonado/. Acesso em 07 de setembro de 2020.

BRAH, Avta. Diferença, diversidade, diferenciação. Cadernos Pagu (26), jan./jul. de 2006. 
BRITO, Carolina Gonçalves Santos de. Transmasculinidades: o direito à identidade de gênero anula o direito ao trabalho? [SYN]THESIS, Rio de Janeiro, vol. 9, oㅜ 1, p. 75-83, jan./jun. 2016.

BOSCHETTI, Ivanete Salete. "Seguridade social na América Latina". In: BOSCHETTI, Ivanete; BEHRING, Elaine Rosseti; SANTOS, Silvana Mara de Morais dos; MIOTO, Regina Célia Tamaso (Orgs). Política Social no Capitalismo: Tendências Contemporâneas. São Paulo: Cortez, 2009.

CACHAPUZ, Julia. "Despejo em plena pandemia: polícia do Rio cerca ocupação que abriga população LGBT". Disponível em: https://revistaforum.com.br/noticias/despejo-na-pandemia-policia-do-rio-cercaocupacao-que-abriga-populacao-lgbt/ Acesso em 07 de setembro de 2020.

CARDOSO, Adalberto. Ensaios de sociologia do mercado de trabalho brasileiro. Rio de Janeiro: Editora FGV, 2013.

CARRARA, S. L.; RAMOS, Silvia. "A Constituição da Problemática da Violência contra Homossexuais: a Articulação entre Ativismo e Academia na Elaboração de Políticas Públicas". PHYSIS: Rev. Saúde Coletiva, Rio de Janeiro, 16(2):185-205, 2006.

CARNEIRO, Sueli. Mulheres em movimento. Estudos Avançados, n. 17 (49), 2003.

CASA DE APOIO BRENDA LEE. Disponível em: https://www.atados.com.br/ong/casa-de-apoio-brenda-lee. Acesso em 07 de setembro de 2020.

CATTANÉO, Nathalie e HIRATA, Helena. Flexibilidade. In: HIRATA, H. et al (orgs.) Dicionário crítico do feminismo. São Paulo: UNESP, 2009.

CFESS. O que é preconceito? Série assistente social no combate ao preconceito. Brasília-DF, 2016.

CISNE, Mirla. Feminismo e consciência de classe no Brasil. São Paulo: Cortez, 2014.

CONNELL, Raewyn. Questões de gênero e justiça social. Século XXI, Revista de Ciências Sociais, v.4, no 2, p.11-48, jan./jun. 2014.

CORTÊZ, Natacha. "Em Copacabana, ocupação oferece acolhimento e refúgio para LGBTQs em situação de vulnerabilidade". Disponível em: https://revistamarieclaire.globo.com/Mulheres-do-Mundo/noticia/2020/04/emcopacabana-ocupacao-oferece-acolhimento-e-refugio-para-Igbtqs-em-situacao-devulnerabilidade.html . Acesso em 07 de setembro de 2020.

GELEDÉS. "Morre a travesti Luana Muniz, símbolo da Lapa". Disponível em: https://www.geledes.org.br/morre-travesti-luana-muniz-simbolo-da-lapa/ Acesso em 07 de setembro de 2020. 
HARTMANN, Jennifer Morel. Transições e resistências: empregabilidade de mulheres trans e travestis em Florianópolis. 2017. 151f. Dissertação (Mestrado em Sociologia Política) - UFSC, Florianópolis.

HELLER, Agnes. O Cotidiano e a História. Tradução de Carlos Nelson Coutinho e Leandro Konder. São Paulo: Paz e Terra, 2008.

IAMAMOTO, Marilda V. Serviço Social em tempo de capital fetiche. 9a ed., São Paulo: Cortez, 2015.

JACCOUD, Luciana. "Programa Bolsa Família: proteção e combate à pobreza no Brasil”. Revista do Serviço Público. Brasília n.64 (3), jul/set. 2013. Disponível em: https://repositorio.enap.gov.br/bitstream/1/1913/1/125-410-1-PB.pdf. Acesso em 07 de setembro de 2020.

KULICK, Don. Travesti: prostituição, sexo, gênero e cultura no Brasil. Rio de Janeiro: Editora Fiocruz. 2008.

LEITE Jr, Jorge. Nossos corpos também mudam: sexo, gênero e as invenções das categorias "travesti" e "transexual" no discurso científico. São Paulo: Annablume, FAPESP, 2011.

LOURO, Guacira Lopes. Gênero, sexualidade e educação. 7. ed. Petrópolis: Vozes, 2004

MARX, Karl. O capital: crítica da economia política: livro I: o processo de produção do capital. Karl Marx; tradução Rubens Enderle. 2. Ed. São Paulo: Boitempo, 2017.

MARINHO, Silvana. Trajetórias em campo minado: juventudes trans e o mundo do trabalho. 2017. 428f. Dissertação (Mestrado em Serviço Social) - UERJ, Rio de Janeiro.

MARINI, Ruy Mauro. Dialética da dependência. Petrópolis: Vozes, 2000.

MIOTO, Regina C. Tamaso. "Família e Serviço Social: contribuições para o debate". Revista Serviço Social e Sociedade. n.55, ano XVI, nov.1997.

MOTA, Ana Elizabete. Cultura da Crise e Seguridade Social: Um estudo sobre as tendências da previdência e da assistência social brasileira nos anos 80 e 90. 6. Ed. São Paulo, Cortez, 2011.

OLIVEIRA, Denilson Araújo de, ALMEIDA, Guilherme, SANTOS, Márcia Cristina Brasil, CARVALHO, Silvia de Souza, PEREIRA, Tatiana Dahmer. "Sobre humanos e destituição de humanidades - da construção do ódio à diferença na modernidade periférica". In: RAMOS, Adriana, BARBOSA, Douglas, PEREIRA, Larissa Dahmer, PEREIRA, Tatiana Dahmer (orgs.). Desenvolvimento, formação social brasileira e políticas públicas: subsídios analíticos para o serviço social. Ubberlândia: Navegando, 2019. 
OLIVEIRA, Tiberio Lima. Meu corpo, um campo de batalha: A inserção precária das travestis no mundo do trabalho em tempos de crise do capital. 2016. 244f. Dissertação (Mestrado em Serviço Social) - UFRN, Natal.

PELÚCIO, Larissa. Abjeção e desejo: uma etnografia travesti sobre o modelo preventivo de aids. São Paulo: Annablume; Fapesp, 2009.

PINO, Nádia Perez. "A teoria queer e os intersex: experiências invisíveis de corpos desfeitos". Dossiê: Sexualidades Disparatadas. Cadernos Pagú. no.28 Campinas jan./jun. 2007.

RAMALHO, Nélson. O trabalho sexual: discursos e práticas dos assistentes sociais em debate. Sexualidad, Salud y Sociedad, n.12, Rio de Janeiro, dez. 2012.

RONDAS, Lincoln de Oliveira; MACHADO, Lucília Regina de Souza. "Inserção profissional de travestis no mundo do trabalho: das estratégias pessoas às políticas de inclusão". Pesquisas e práticas psicossociais, n. 10, São João del-Rey, janeiro/junho. 2015

SCOTT, Joan Wallach. A mulher Trabalhadora. In: DUBY, Georges, PERROT, Michelle. História das mulheres no Ocidente: o século XIX. Tradução de Cláudia Gonçalves e Egito Gonçalves. Porto: Edições Afrontamento; São Paulo: Ebradil, 1991.

VICTORA, Ceres Gomes; KNAUTH, Daniela Riva; HASSEN, Maria de Nazaré. Pesquisa Qualitativa em Saúde: uma introdução ao tema. Porto Alegre: Tomo Editorial, 2000.

VINODJ. "Casa Nem é realocada pelo governo do estado do Rio". Rio Gay Life. 24 de agosto de 2020. Disponível em: https://riogaylife.com.br/casa-nem-e-realocadapelo-governo-do-estado-do-rio/ Acesso em 07 se setembro de 2020. 